\title{
You and me
}

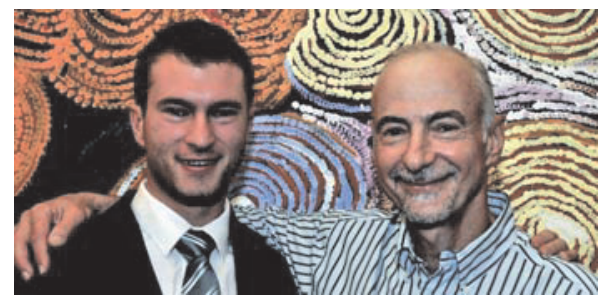

\section{Dr Hilton Immerman and Dr Josef McDonald} ("Macca") speak of their association as mentor and Indigenous medical student

\section{Hilton}

n late 2004, Macca successfully completed the bridging course for Indigenous students to gain entry to the University of New South Wales (UNSW). He started the 6-year Medicine degree in March 2005. Since he is from the Newcastle area, he had to find accommodation near campus for his first year-and-a-half. However, he and his family were no longer able to cover the high cost of his accommodation. He had also felt alienated living where he was and was uncomfortable about revealing his Indigenous identity.

In 2005, we had just established the Shalom Gamarada Indigenous Scholarship Program, which provides board and lodging, tutoring and other forms of support at Shalom College - the college I have been running since 1989.

Macca succeeded in gaining a scholarship in July 2006. He received the Sabina Ross Slater Memorial Medical Scholarship, which was provided by Edna Ross in memory of her mother, who had died the year before.

I remember interviewing him. He had a sense of humour and a mischievous sparkle in his eyes. I sensed that he might prove a handful as a resident of a UNSW college with an academic culture, accommodating 129 other students.

My intuition was proven right. Macca for me exemplified the wonderful Aussie term "larrikin". In the early years of his studies, he was a bit of a rascal and scallywag - but one with endearing qualities. If ever there were pranks or mischief in college, chances were that Macca was involved! On quite a few occasions, I had to summon him to my office to discuss his youthful indiscretions.

As stern as I tried to be, I suspect that I never really succeeded in concealing the fact that I was genuinely fond of and believed in him.

In 2007, I was invited to speak about Shalom College's Indigenous scholarship program to a chapter of Rotary. I proposed that one of our scholarship students would join me and talk about it from his perspective. To be honest, my first choice was a more senior female scholarship holder, but she was not available at the time. So, I decided to take the plunge and ask Macca if he would accompany me.
During his talk, to a crowded room, he commented on his former experiences of racism and self-doubt and explained how, ironically, a Jewish college had given him the opportunity to explore and take pride in his Indigenous identity for the first time. At this point, he was so filled with emotions about which he had not previously spoken publicly, that he burst into tears. There were not many dry eyes in the room - mine included!

Each year since the scholarship has been running, we have held a Shalom Gamarada Aboriginal Art Exhibition to publicise and raise funds for it. This is an excerpt of what Macca wrote for a display board:

"Receiving the Shalom Gamarada Scholarship has been a life-changing experience for me. Apart from the advantages it offers my studies, another great benefit of the program is that it offers a racism-free environment in which Indigenous students can live and discuss Indigenous issues and what it means to be Indigenous.

"Without it, [the scholarship] it would be impossible for ironically, a Jewish college had given him the opportunity to explore and take pride in his Indigenous identity for the first time

$5 y$
me to study medicine as there is no way my family could afford for me to live in Sydney."

At the end of 2008, after Macca had successfully completed his 4th Year, he decided to defer his studies in 2009 to support his family over a difficult period. Some had doubts about whether he would return and I confess to sharing their concerns.

I endeavoured to keep in touch with him over the course of the year and to involve him in various scholarship-related activities, including the annual art fair. He has always been generous with his time and this was no exception.

Macca came back to Shalom College and his studies in 2010. In semester 2 of 2010, he successfully applied to become a college tutor - a role he has ably filled since. He's been a great mentor and role model to other students, both Indigenous and non-Indigenous.

At the recent formal dinner for the new bridging course run by the Nura Gili Indigenous centre at UNSW, Macca was one of four UNSW students interviewed. At the end, he was asked if he had any words of advice for the new students. After deliberating briefly, he said: "If you succeed in getting into medicine and law next year, you're likely to feel like an imposter. I did. Your peers in the program will be the brightest and most privileged students from around Australia and the world. Many will have come from exclusive, private schools. Most of you come from underprivileged and disadvantaged backgrounds. But, you must never forget that you will have earned your place in your course. You deserve to be there and you owe it to yourselves, your families and your communities to succeed. You can and must!"
Hilton Immerman CEO

Shalom College, University of New South Wales, Sydney, NSW.

doi: 10.5694/mjal2.10032 
I feel so much emotion and pride in him when I reflect on how he has grown from being a mischievous adolescent, who was frequently in trouble in college, to a mature and wise adult.

On 16 December 2011, I was a member of the academic procession at the UNSW graduation ceremony at which he formally became a doctor. 